\title{
Inhibitory Effects of Indirubin-3'-oxime Derivatives on Lipid Accumulation in 3T3-L1 Cells
}

\author{
Yasuhito Nobushi,* Hiroaki Saito, Shinichi Miyairi, Taketo Uchiyama, and Yukinaga Kishikawa \\ School of Pharmacy, Nihon University; 7-7-1 Narashinodai, Funabashi, Chiba 274-8555, Japan. \\ Received October 14, 2019; accepted December 19, 2019
}

\begin{abstract}
Obesity elevates the risk of cardiovascular disease and has been strongly associated with increases in the incidence of many metabolic diseases. Therefore, prevention of obesity leads to the prevention of metabolic diseases. In light of this, substances that exert anti-obesity effects are crucial for the prevention of obesity. Indirubin, a 3,2' bisindole isomer of indigo, is the active component of the traditional Chinese medicine used for the treatment of chronic myelocytic leukemia. In particular, indirubin-3'-oxime (1) was shown to inhibit the differentiation of adipocytes. In this study, we investigated the inhibitory effects of nine indirubin-3'-oxime derivatives against lipid accumulation during differentiation in 3T3-L1 cells. Among the compounds tested, 5-methoxyindirubin-3'-oxime (2) and 6-bromoindirubin-3'-oxime (7) at $5 \mu \mathrm{M}$ exhibited significantly stronger inhibitory activity than indirubin-3'-oxime (1). Furthermore, 5-methoxyindirubin-3'-oxime (2) and 6-bromoindirubin-3'-oxime (7) markedly suppressed the expression of CCAAT/enhancer-binding protein $\alpha$, peroxisome proliferator activator $\gamma 2$, and adipocyte protein 2 , both of which are key adipogenic regulators at the intermediate stage of adipocyte differentiation. Our results demonstrate that 5-methoxyindirubin-3'-oxime (2) and 6-bromoindirubin-3'-oxime (7) significantly downregulated lipid accumulation during differentiation of 3T3-L1 cells, suggesting their potential as novel therapeutic drugs against the development of obesity.
\end{abstract}

Key words indirubin-3'-oxime derivative; 3T3-L1 cell; obesity; lipid accumulation

\section{INTRODUCTION}

Obesity is currently one of the greatest social problems in Japan. It increases the risk of cardiovascular disease and has been strongly associated with increases in the incidence of metabolic diseases, such as hypertension, type 2 diabetes, insulin resistance, dyslipidemia, and atherosclerosis. ${ }^{1-6)}$ Therefore, improving and preventing obesity leads to the prevention of metabolic diseases. Over the last few decades, considerable attention has been focused on the improvement of obesity, therapeutic treatments, and the molecular mechanism of adipocyte differentiation. $^{7-9)}$ 3T3-L1 cells have been extensively used in anti-obesity studies. ${ }^{10-12)}$ Therefore, these cells are a useful model in screening novel agents for the prevention of obesity and clarifying the molecular mechanism of adipocyte differentiation. We previously reported the inhibitory effects of triterpenoids and chalcones isolated from Brazilian propolis and leaves of Murta (Myreugenia euosma), respectively, against lipid accumulation during differentiation of 3T3-L1 cells. $^{13-15)}$

Indirubin, a 3,2' bisindole isomer extracted from the indigo plant, has been identified as the active component of Danggui Longui Wan, a traditional Chinese medicine used for the treatment of chronic myelocytic leukemia. ${ }^{16)}$ Indirubin derivatives have also been reported to inhibit protein kinases, such as cyclin-dependent kinases and glycogen synthase kinase-3. ${ }^{17-20)}$ Our previous studies have also reported that some of these derivatives exhibit beneficial pharmacological effects, such as anti-cancer and anti-inflammatory activities. ${ }^{21-24)}$ Interestingly, indirubin-3'-oxime has been demonstrated to inhibit the differentiation of adipocytes. ${ }^{25)}$ However, it remains unclear whether indirubin-3'-oxime derivatives exert their inhibitory effects against lipid accumulation during differentiation of 3T3-L1 cells. In the present study, we investigated the inhibitory effect of nine indirubin-3'-oxime derivatives on lipid accumulation during differentiation of 3T3-L1 cells.

\section{MATERIALS AND METHODS}

Indirubin-3'-oxime Derivatives The structures of the indirubin-3'-oxime derivatives are shown in Fig. 1. These compounds were prepared as previously reported. ${ }^{23,26)}$

Materials Dulbecco's modified Eagle's medium (DMEM) and Ham's F12 medium were purchased from Nissui Pharmaceutical Co., Ltd. (Tokyo, Japan). Calf serum was obtained from Thermo Fisher Scientific (Waltham, MA, U.S.A.). Fetal bovine serum and Oil Red $\mathrm{O}$ were obtained from Cosmo Bio. Co., Ltd. (Tokyo, Japan). Isobutyl-3-methylxanthine, dexamethasone, insulin, adenine, transferrin, glutamine, and dimethyl sulfoxide (DMSO) were obtained from Wako Pure Chemical Industries, Ltd. (Osaka, Japan). Triiodothyronine was obtained from Sigma-Aldrich Co. (St. Louis, MO, U.S.A.). Penicillin-streptomycin-glutamine and penicillinstreptomycin-neomycin were purchased from Life Technologies (Burlington, ON, Canada). The 3-(4,5-dimethylthiazol2-yl)-2,5-diphenyltetrazolium bromide (MTT) Cell Counting Kit (MTT) was obtained from Nacalai Tesque Inc. (Kyoto, Japan).

Cell Culture The 3T3-L1 cells (Human Science Research Resources Bank, Osaka, Japan) were cultured in DMEM supplemented with $10 \%$ calf serum and $1 \%$ penicillin-streptomycinglutamine in an incubator at $37^{\circ} \mathrm{C}$ with $5 \%$ carbon dioxide. Subsequently, 3T3-L1 cells were seeded in 24-well plates and $6-\mathrm{cm}$ dishes. The cells were grown to confluence to induce ad- 


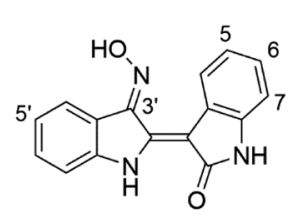<smiles>COc1ccc2c(c1)/C(=C1/Nc3ccccc3C1=O)C(=O)N2</smiles>

Indirubin-3'-oxime (1) 5-Methoxyindirubin-3'-oxime (2)

6-Methoxyindirubin-3'-oxime (3)<smiles>COc1cccc2c1NC(=O)C2=C1Nc2ccccc2C1=NO</smiles><smiles>COc1ccc2c(c1)/C(=C1/C(=O)Nc3ccccc31)NC2=O</smiles><smiles>COc1ccc2c(c1)NC(=O)/C2=C1\Nc2ccccc2\C1=N/O</smiles><smiles>O=C1Nc2ccc(Br)cc2/C1=C1/Nc2ccccc2/C1=N/O</smiles>

5-Bromoindirubin-3'-oxime (6)<smiles>O=C1Nc2ccccc2/C1=C1\Nc2ccc(Br)cc2\C1=N/O</smiles>

5'-Bromoindirubin-3'-oxime (9)

Fig. 1. Structures of the Nine Indirubin-3'-oxime Derivatives Used in This Study

ipose differentiation. The cells were induced with differentiation medium (DMEM and Ham's F12 supplemented with 10\% fetal bovine serum, $1 \%$ penicillin-streptomycin-neomycin, $1.6 \mu \mathrm{M}$ insulin, $0.0005 \%$ transferrin, $180 \mu \mathrm{M}$ adenine, $20 \mathrm{pM}$ triiodothyronine) containing $500 \mu \mathrm{M}$ isobutyl-3-methylxanthine, and $0.25 \mu \mathrm{M}$ dexamethasone with indirubin-3'-oxime derivatives (defined as $0 \mathrm{~d}$ ). After 2 and $4 \mathrm{~d}$, the cell culture medium containing indirubin-3'-oxime derivatives was replaced with fresh differentiation medium. The test samples were dissolved in DMSO. The final concentration of DMSO in the differentiation medium was $0.1 \%$.

Cell Viability Assay Cell viability was measured using the MTT assay. The 3T3-L1 cells $\left(1 \times 10^{4}\right.$ cells/well $)$ were seeded in a 96-well plate. After $2 \mathrm{~d}$ of incubation, the cells were treated with indirubin-3'-oxime derivatives at $5 \mu \mathrm{M}$. After $48 \mathrm{~h}, 10 \mu \mathrm{L}$ MTT solution $(5.0 \mathrm{mg} / \mathrm{mL})$ was added to each well, and the plate was incubated for an additional $4 \mathrm{~h}$ at $37^{\circ} \mathrm{C}$. Subsequently, $100 \mu \mathrm{L}$ MTT solubilization solution was added. Cell viability was calculated by determining the absorbance at $570 \mathrm{~nm}$ using a microplate reader.

Oil Red O Staining The 3T3-L1 cells $\left(5 \times 10^{4}\right.$ cells/well $)$ were seeded in a 24 -well plate. At day 7 , the cultured cells were washed with phosphate-buffered saline and fixed with $10 \%$ formalin for $24 \mathrm{~h}$. The fixed cells were then rinsed once with $\mathrm{H}_{2} \mathrm{O}$, and stained with Oil Red $\mathrm{O}$ solution $(0.5 \%$ Oil Red $\mathrm{O}$ in $60 \%$ isopropanol, and filtered with a $1.0-\mu \mathrm{m}$ filter) for $15 \mathrm{~min}$. The stained cells were washed thrice with $\mathrm{H}_{2} \mathrm{O}$ prior to visualization and documentation. The Oil Red $\mathrm{O}$ was eluted using a solubilization solution ( $99 \%$ isopropanol), and quantified by measuring the absorbance at $540 \mathrm{~nm}$ using a microplate reader. The value of DMSO-treated cells was defined as $100 \%$.

Gene Expression The 3T3-L1 cells $\left(2 \times 10^{5}\right.$ cells/well $)$ were seeded in $6-\mathrm{cm}$ plates. At day 7, total RNA was isolated from 3T3-L1 cells using RNAiso Plus (TaKaRa Co., Ltd., Shiga, Japan). RNA $(1.0 \mu \mathrm{g})$ was used for cDNA synthesis
Table 1. Primers Used in This Study

\begin{tabular}{cll}
\hline \hline Gene & Primers & \multicolumn{1}{c}{$\left(5^{\prime}-3^{\prime}\right.$ Sequence $)$} \\
\hline Ppary 2 & Forward & GCTGTTATGGGTGAAACTCTG \\
& Reverse & ATAATAAGGTGGAGATGCAGG \\
Clebpa & Forward & TGGACAAGAACAGCAACGAG \\
& Reverse & TCACTGGTCAACTCCAGCAC \\
aP2 & Forward & ATGAAATCACCGCAGACGACAGGA \\
& Reverse & TGTGGTCGACTTTCCATCCCACTT \\
Atgl & Forward & GGAGACCAAGTGGAACATCTCA \\
& Reverse & AATAATGTTGGCACCTGCTTCA \\
Hsl & Forward & TCCTGGAACTAAGTGGACGCAAG \\
& Reverse & CAGACACACTCCTGCGCATAGAC \\
Ppard & Forward & ATGCCAGTACTGCCCTTTTC \\
& Reverse & GGCCTTGACCTTGTTCATGT \\
Ucp 2 & Forward & GGCTGGTGGTGGTCGGAGAT \\
& Reverse & CCGAAGGCAGAAGTGAAGTG \\
$36 b 4$ & Forward & AAGCGCGTCCTGGCATTGTCT \\
& Reverse & CCGCAGGGGCAGCAGTGGT \\
\hline
\end{tabular}

with oligo primers (Sigma-Aldrich Co.), deoxynucleoside triphosphate mixture (Nippon gene Co., Ltd., Tokyo, Japan), and reverse transcriptase (Toyobo Co., Ltd., Osaka, Japan). Aliquots of cDNA were amplified using a Stratagene Mx3000 quantitative RT-PCR (Agilent Technologies, Santa Clara, CA, U.S.A.) by GoTap qPCR Master Mix (Promega, Madison, WI, U.S.A.) according to the protocol provided by the manufacturer. The primer sequences (Sigma-Aldrich Co.) used in this study are shown in Table 1 . The relative mRNA expression was normalized against the expression of $36 \mathrm{~b} 4$.

Statistical Analysis The data are presented as the mean \pm standard deviation. All data analyses were conducted using ANOVA. The statistical significance of differences between DMSO and test samples was determined using Tukey's test. $p$-Values $<0.05$ denoted statistical significance. 


\section{RESULTS}

Effect of Nine Indirubin-3-oxime Derivatives (1-9) on Lipid Accumulation in 3T3-L1 Cells Indirubin-3'-oxime (1) has been shown to inhibit the differentiation of adipocytes. ${ }^{25)}$ Firstly, we confirmed whether indirubin-3'-oxime (1) acts as an inhibitor of adipocyte differentiation in 3T3-L1 preadipocytes for $7 \mathrm{~d}$, using Oil Red $\mathrm{O}$ staining. The results demonstrated that treatment with indirubin-3'-oxime (1) significantly inhibited lipid accumulation during differentiation in a dose-dependent manner (Fig. 2). Secondly, the effect of the nine indirubin-3-oxime derivatives on cell viability was evalu-

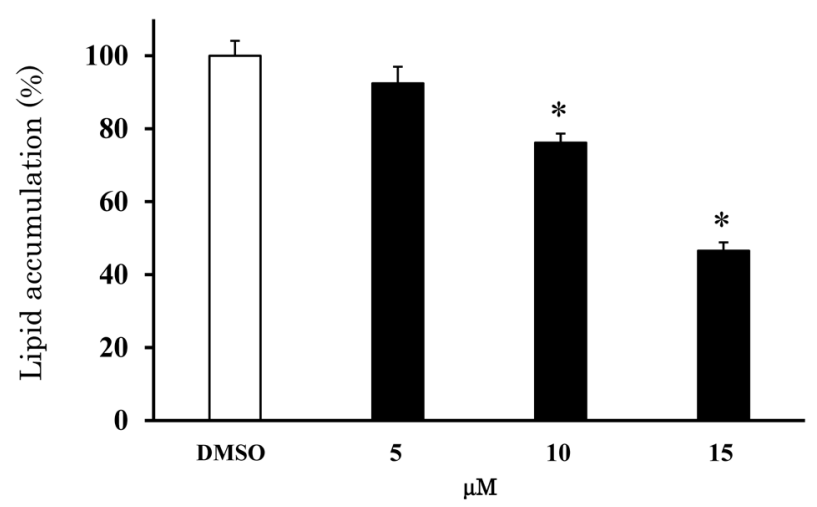

Fig. 2. Concentration-Dependent Effect of Indirubin-3'-oxime (1) on Lipid Accumulation in 3T3-L1 Cells

The cells were treated with compound 1 on days 0,2 , and 4 . The levels of intracellular lipids were assayed using Oil Red O staining $7 \mathrm{~d}$ after the induction of differentiation. Results are the mean \pm standard deviation (S.D.) of three independen experiments $(* p<0.05 v s$. control, Tukey's test). The value obtained using DMSOtreated cells was $100 \%$

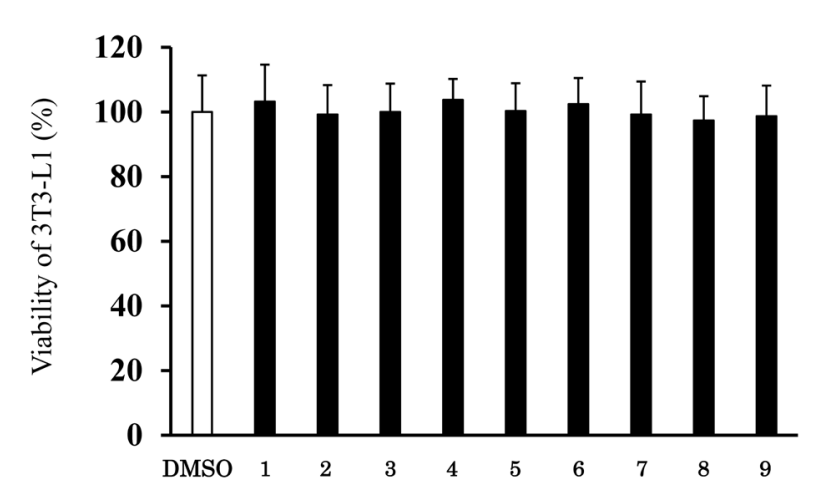

Fig. 3. Effects of Indirubin Derivatives 1-9 $(5 \mu \mathrm{M})$ on the Viability of 3T3-L1 Cells

The cells were treated with each of the nine compounds. Cytotoxicity was assessed on day 2 using MTT assay. Results are means \pm S.D. of three independent experiments $(* p<0.05 v s$. control, Tukey's test). The value obtained with DMSOtreated cells was $100 \%$.

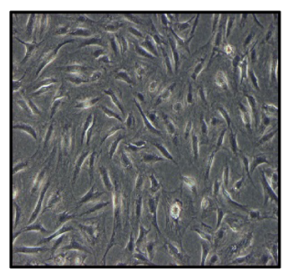

No addition

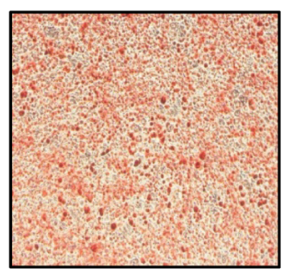

DMSO ated using the MTT assay. None of the indirubin-3'-oxime derivatives were cytotoxic at concentrations up to $5 \mu \mathrm{M}$ (Fig. 3). Subsequent experiments were performed with indirubin3-oxime derivatives at concentrations up to $5 \mu \mathrm{M}$. Oil Red O staining was conducted after induction of differentiation for $7 \mathrm{~d}$ to investigate the effects of the indirubin-3-oxime derivatives (1-9) on lipid accumulation. After induction, complete differentiation was observed in DMSO-treated control cells, whereas treatment with 5-methoxyindirubin-3'-oxime (2) and 6-bromoindirubin-3'-oxime (7) significantly inhibited lipid accumulation during differentiation (Fig. 4). The presence of methoxy group in 5-position is important for decreasing lipid accumulation. Moving the methoxy group from the 5-position to the other sites was detrimental (2 vs. 3-5). In addition, incorporation of the bromine in the 5-position (6) especially in the 6-posion (7) increased activity. The quantitative analysis of Oil Red $\mathrm{O}$ staining also revealed that treatment with 5-methoxyindirubin-3'-oxime (2) and 6-bromoindirubin-3'-oxime (7) drastically attenuated lipid accumulation compared with DMSO and indirubin-3'-oxime (1) (Fig. 5). It is well established that berberine chloride can act as an inhibitor of lipid accumulation during the differentiation of 3T3-L1 cells. Hence, berberine chloride at $5 \mu \mathrm{M}$ was used as a positive control. ${ }^{27)}$ 5-Methoxyindirubin-3'-oxime (2) and 6-bromoindirubin-3'-oxime (7) exhibited a similar inhibitory activity on lipid accumulation to that observed for berberine chloride. As shown in Fig. 6, 5-methoxyindirubin-3'-oxime (2) and 6-bromoindirubin-3'-oxime (7) effectively decreased the level of lipid accumulation in 3T3-L1 cells in a dose-dependent manner. Our results show that 5-methoxyindirubin-3'-oxime

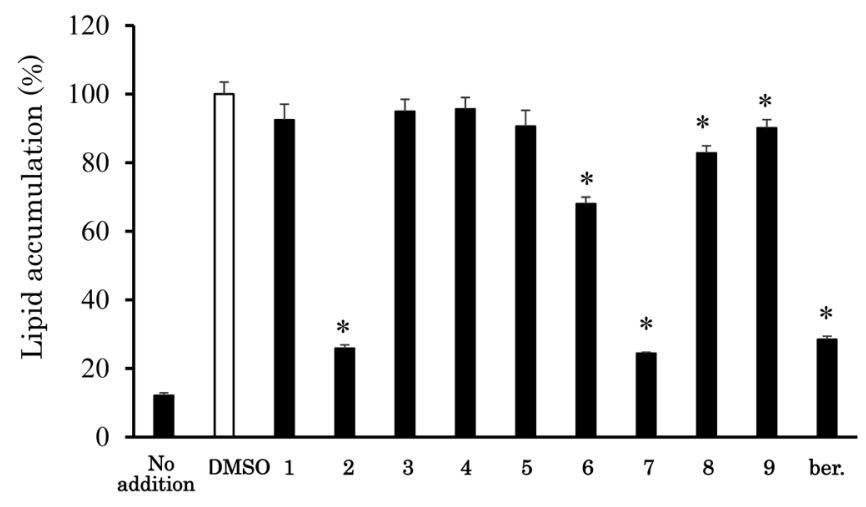

Fig. 4. Effects of Indirubin Derivatives 1-9 $(5 \mu \mathrm{M})$ on Lipid Accumulation in 3T3-L1 Cells

Berberine chloride (ber.) $(5 \mu \mathrm{M})$ was used as a positive control. The cells were treated with each of the nine compounds on days 0,2 , and 4 . The levels of intracellular lipids were assayed using Oil Red $\mathrm{O}$ staining $7 \mathrm{~d}$ after the induction of differentiation. Results are the mean \pm S.D. of three independent experiments $(* p<0.05$ vs. control, Tukey's test). The value obtained with DMSO-treated cells was $100 \%$.

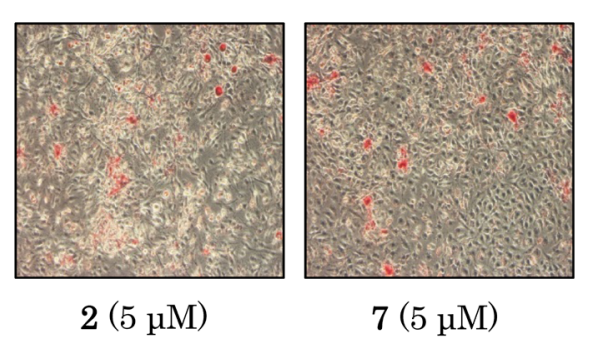

Fig. 5. Oil Red O Staining of Control (DMSO) and 5-Methoxyindirubin-3'-oxime (2) and 6-Bromoindirubin-3'-oxime (7)-Treated 3T3-L1 Cells (Color figure can be accessed in the online version.) 

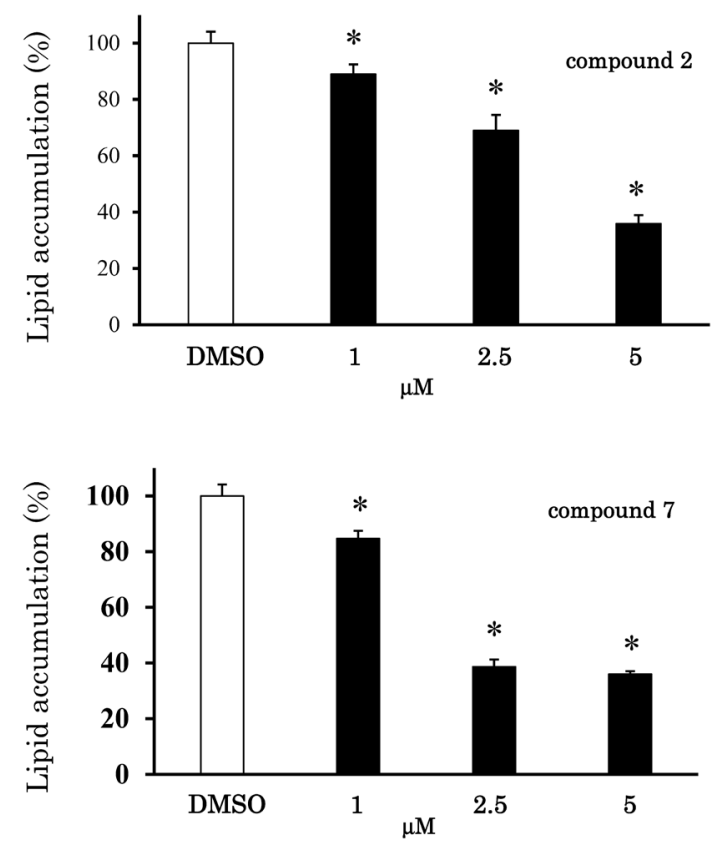

Fig. 6. Concentration-Dependent Effects of 5-Methoxyindirubin-3'oxime (2) and 6-Bromoindirubin-3'-oxime (7) on Lipid Accumulation in 3T3-L1 Cells

The cells were treated with compound $\mathbf{2}$ and 7 on days 0,2 , and 4 . The levels of intracellular lipids were assayed using Oil Red O staining $7 \mathrm{~d}$ after the induction of differentiation. Results are the mean \pm S.D. of three independent experiment $(* p<0.05$ vs. control, Tukey's test). The value obtained using DMSO-treated cells was $100 \%$.

(2) and 6-bromoindirubin-3'-oxime (7) had significantly stronger inhibitory activity than indirubin-3'-oxime (1).

Effect of Indirubin Derivatives 2 and 7 on the Gene Expression of Adipocyte Differentiation Markers in 3T3-L1 Cells CAA T/enhancer-binding protein (C/EBP) $\alpha$ and peroxisome proliferator activator receptor (PPAR) $\gamma 2$ play roles as master regulators of adipogenesis and induce the expression of lipogenic proteins, such as adipocyte protein 2 (aP2). ${ }^{28-30)}$ We examined the expression levels of major adipocyterelated genes (Ppary2, Clebpo, and aP2) to investigate the inhibitory mechanism of 5-methoxyindirubin-3'-oxime (2) and 6-bromoindirubin-3'-oxime (7) during differentiation. As shown in Fig. 7A, differentiated cells clearly displayed increased expression levels of these genes compared with undifferentiated cells. In contrast, 5-methoxyindirubin-3'-oxime (2) and 6-bromoindirubin-3'-oxime (7) down-regulated the expression levels of these genes compared with DMSO. Moreover, adipose triglyceride lipase (ATGL) and hormonesensitive lipase (HSL) has been shown to be involved in the lipolysis of triacylglycerol in adipocytes. ${ }^{31)}$ Furthermore, $\operatorname{PPAR} \alpha$ and uncoupling protein 2 (UCP2) are known to play a role in lipid metabolism. ${ }^{32,33)}$ We also measured the expression levels of genes related to lipolysis and lipid metabolism. The results show that 5-methoxyindirubin-3'-oxime (2) and 6-bromoindirubin-3'-oxime (7) inhibited the expression levels of the lipolysis and lipid metabolism-related genes (Figs. 7B, C). These findings suggest that 5-methoxyindirubin-3'-oxime (2) and 6-bromoindirubin-3'-oxime (7) exert an inhibitory effect during the differentiation of 3T3-L1 cells. Therefore, 5methoxyindirubin-3'-oxime (2) and 6-bromoindirubin-3'-oxime (7) may represent lead compounds in the development of agents for the prevention of obesity.

\section{DISCUSSION}

The inhibitory effect of indirubin-3'-oxime (1) on adipocyte differentiation has been reported. ${ }^{25)}$ The molecular mechanisms of adipocyte differentiation have been extensively examined using cultured pre-adipocytes, such as 3T3-L1 cells. Thus, these cells are a suitable screening model to assess the anti-obesity effects of agents and natural products. In the present study, we examined the inhibitory effects of indirubin-3'-oxime derivatives against adipocyte differentiation using 3T3-L1 cells. We selected indirubin-3'-oximes with different substituent types (i.e., methoxy group as an electron-donating group and bromine as an electronwithdrawing group) to obtain information regarding the substituents and electron density of the aromatic ring of the indirubin skeleton. Among the nine indirubin-3'-oxime derivatives selected, 5-methoxyindirubin-3'-oxime (2) and 6-bromoindirubin-3'-oxime (7) demonstrated stronger inhibitory activity than indirubin-3'-oxime (1). The data shown in Fig. 4 indicate the need of a methoxy group in the 5-position and a bromine in the 6-position. The bromine substitution in the 6-position is seems to be important for selectivity of indirubin analogs toward critical physiological kinases (GSK-3 and $\mathrm{CDKs}){ }^{19)}$ Interestingly, insertion of these substituents in the 5 -position instead of the 5-position was detrimental for lipid accumulation (Fig. 4). Also, indirubin-3'-oxime derivatives were not cytotoxic at concentrations up to $5 \mu \mathrm{M}$. Thus, the results of the cell viability analysis suggest that the inhibitory effects of 5-methoxyindirubin-3'-oxime (2) and 6-bromoindirubin-3'-oxime (7) on lipid accumulation during cell differentiation are attributable to their anti-lipogenic properties. Moreover, berberine chloride was used as a positive control. ${ }^{27)}$ The results show that 5-methoxyindirubin-3'-oxime (2) and 6-bromoindirubin-3'-oxime (7) exhibit a similar inhibitory effect on lipid accumulation to that reported for berberine chloride.

Adipogenesis is accompanied by the expression of various adipocyte-related genes. $\mathrm{C} / \mathrm{EBP} \alpha$ and $\operatorname{PPAR} \gamma 2$ are the master regulators of adipogenesis, and are activated during the intermediate stages of adipocyte differentiation. ${ }^{28-30)} \mathrm{aP} 2$ is expressed in differentiated adipocytes and plays a role in fatty acid metabolism. We confirmed that 5-methoxyindirubin-3'-oxime (2) and 6-bromoindirubin-3'-oxime (7) suppressed the expression levels of the adipocyte-related genes Ppary2, Clebpo, and $a P 2$. These results demonstrate that 5-methoxyindirubin-3'-oxime (2) and 6-bromoindirubin-3'-oxime (7) inhibit the differentiation of 3T3-L1 preadipocytes by suppressing the expression of Ppary2 and Clebpa. In addition, 5-methoxyindirubin-3'-oxime (2) and 6-bromoindirubin-3'-oxime (7) inhibited the expression of the lipolysis and the lipid metabolism-related genes Atgl, Hsl, Ppara, and Ucp2, which was not significantly different from the expression levels in undifferentiated cells. Although the precise structure-activity relationships and inhibition mechanisms have not yet been clarified, these results provide new directions for designing 5- and/or 6-substituted indirubins ${ }^{19,20,23)}$ that could potentially be applied to the prevention of obesity. Further studies are warranted to elucidate the direct association between the inhibition of lipid accumulation and the structure of indirubin-3'-oximes. 
(A)
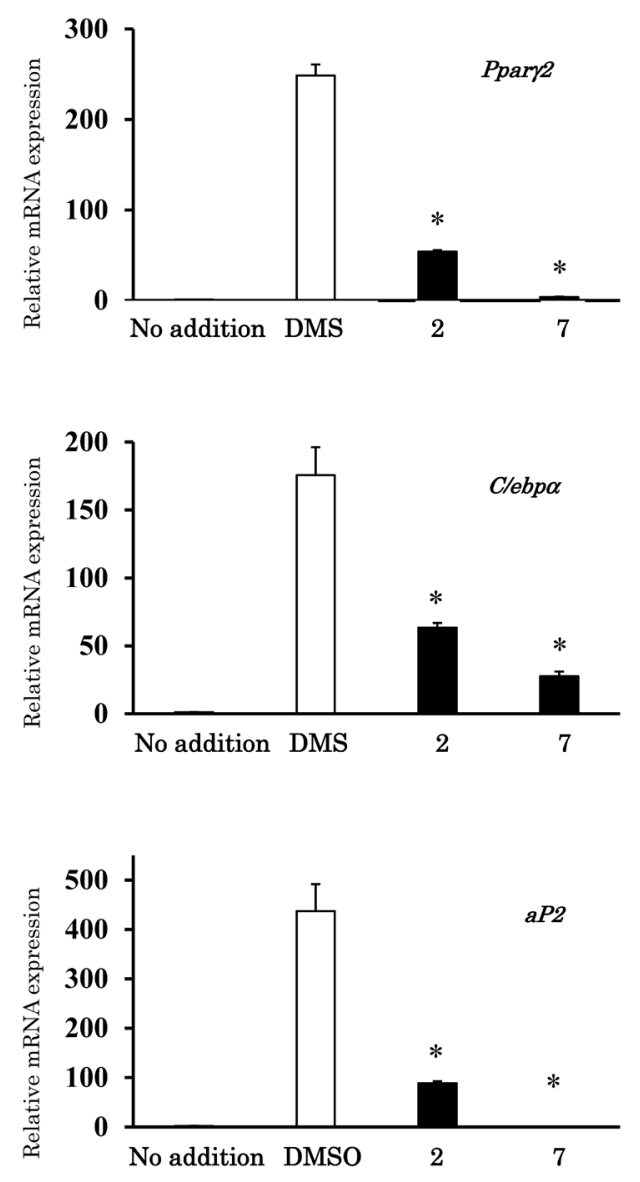

(B)
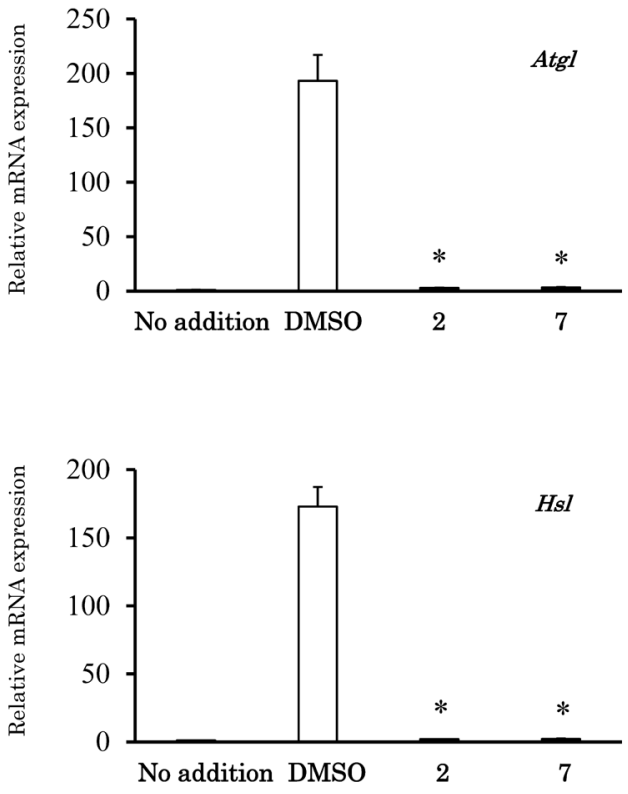

(C)
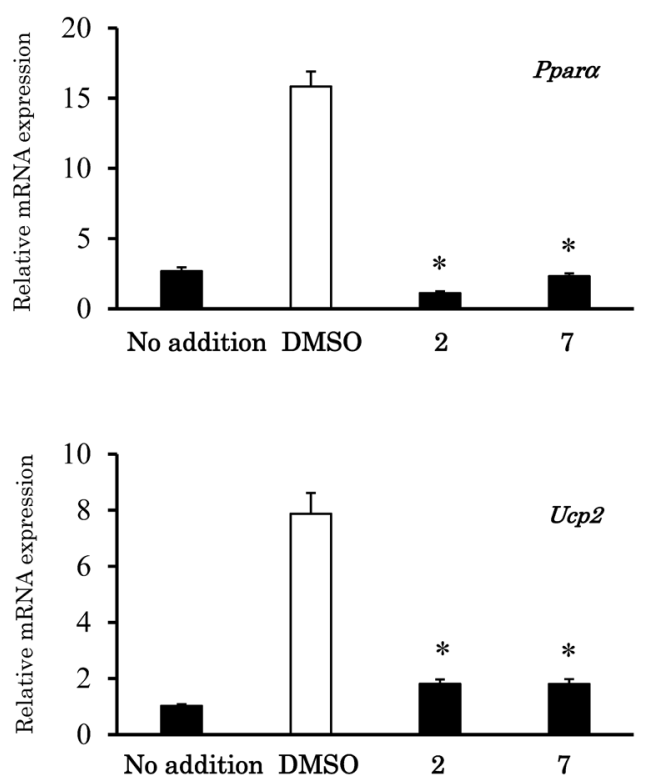

Fig. 7. Quantitative Real-Time PCR Assay for the mRNA Expression of (A) Ppary2, Clebp $\alpha$, and aP2, (B) Atgl and Hsl, (C) Ppara and Ucp2 in 3T3-L1 Cells on Day 7

The cells were treated with compound 2 and $7(5 \mu \mathrm{M})$ or DMSO as a control. The expression of the Ppar 2 , Clebpa, aP2, Atgl, Hsl, Ppara, and Ucp2 genes was normalized to that of $36 b 4$ (loading control). Results are the mean \pm S.D. of three independent experiments $(* p<0.05 v s$. control, Tukey's test).

\section{CONCLUSION}

In the present study, we found that indirubin- 3 '-oxime derivatives exhibit an inhibitory effect against lipid accumulation during differentiation of 3T3-L1 cells. The results showed that 5-methoxyindirubin-3'-oxime (2) and 6-bromoindirubin-3'-oxime (7) exhibited significantly stronger inhibitory activity than indirubin-3'-oxime (1). In addition, 5-methoxyindirubin-3'-oxime (2) and 6-bromoindirubin-3'-oxime (7) suppressed adipocyte differentiation, and was involved in the down-regulation of key adipogenic regulators (i.e., Ppary2, Clebpo). The present study is the first to investigate the anti-obesity effect of indirubin-3'-oxime derivatives. These results suggest that 5-methoxyindirubin-3'-oxime (2) and 6-bromoindirubin-3'-oxime
(7) may represent lead compounds in the development of agents for the prevention of obesity.

Acknowledgments Development and Establishment of the Center of Excellence on Anti-Doping Education Research, and Studies toward Post-Olympic/Paralympic Games at Nihon University. The authors thank Dr. Koichi Metori from the Institute of Pharmaceutical Sciences, Nihon University, for performing the mass measurements.

Conflict of Interest The authors declare no conflict of interest. 


\section{REFERENCES}

1) Kopelman PG. Obesity as a medical problem. Nature, 404, 635-643 (2000).

2) Larsen TM, Toubro S, Astrup A. PPARgamma agonists in the treatment of type II diabetes: is increased fatness commensurate with long-term efficacy? Int. J. Obes., 27, 147-161 (2003).

3) Formiguera X, Canton A. Obesity: epidemiology and clinical aspects. Best Pract. Res. Clin. Gastroenterol., 18, 1125-1146 (2004).

4) Mann CC. Public health. Provocative study says obesity may reduce U.S. life expectancy. Science, 307, 1716-1717 (2005).

5) Kahn SE, Hull RL, Utzschneider KM. Mechanisms linking obesity to insulin resistance and type 2 diabetes. Nature, 444, 840-846 (2006).

6) Matsuzawa Y. The metabolic syndrome and adipocytokines. FEBS Lett., 580, 2917-2921 (2006).

7) Ahn J, Lee H, Kim S, Park J, Ha T. The anti-obesity effect of quercetin is mediated by the AMPK and MAPK signaling pathways. Biochem. Biophys. Res. Commun., 373, 545-549 (2008).

8) Ogawa T, Tabata H, Katsube T, Ohta Y, Yamasaki Y, Yamasaki M, Shiwaku K. Suppressive effect of hot water extract of wasabi (Wasabia japonica Matsum.) leaves on the differentiation of 3T3-L1 preadipocytes. Food Chem., 118, 239-244 (2010).

9) Yahagi T, Daikonya A, Kitanaka S. Flavonol acylglycosides from flower of Albizia julibrissin and their inhibitory effects on lipid accumulation in 3T3-L1 cells. Chem. Pharm. Bull., 60, 129-136 (2012).

10) Rosen ED, Spiegelman BM. Molecular regulation of adipogenesis. Annu. Rev. Cell Dev. Biol., 16, 145-171 (2000).

11) Ahn J, Lee H, Kim S, Park J, Ha T. The anti-obesity effect of quercetin is mediated by the AMPK and MAPK signaling pathways. Biochem. Biophys. Res. Commun., 373, 545-549 (2008).

12) Wada T, Ihunnah CA, Gao J, Chai X, Zeng S, Philips BJ, Rubin JP, Marra KG, Xie W. Estrogen sulfotransferase inhibits adipocyte differentiation. Mol. Endocrinol., 25, 1612-1623 (2011).

13) Nobushi Y, Hamada Y, Yasukawa K. Inhibitory effects of the edible mushroom Flammulina velutipes on lipid accumulation in 3T3-L1 cells. J. Pharm. Nutr. Sci., 3, 222-227 (2013).

14) Nobushi Y, Oikawa N, Okazaki Y, Tsutsumi S, Park YK, Kurokawa M, Shimba S, Yasukawa K. Inhibitory effects of Brazilian propolis on lipid accumulation in 3T3-L1 cells. J. Pharm. Nutr. Sci., 4, 6-11 (2014).

15) Oikawa N, Nobushi Y, Wada T, Sonoda K, Okazaki Y, Tsutsumi S, Park YK, Kurokawa M, Shimba S, Yasukawa K. Inhibitory effects of compounds isolated from the dried branches and leaves of murta (Myrceugenia euosma) on lipid accumulation in 3T3-L1 cells. $J$. Nat. Med., 70, 502-509 (2016).

16) Xiao Z, Hao Y, Liu B, Qian L. Indirubin and meisoindigo in the treatment of chronic myelogenous leukemia in China. Leuk. Lymphoma, 43, 1763-1768 (2002).

17) Hoessel R, Leclerc S, Endicott JA, Nobel MEM, Lawrie A, Tunnah P, Leost M, Damiens E, Marie D, Marko D, Niederberger E, Tang W, Eisenbrand G, Meijer L. Indirubin, the active constituent of a Chinese antileukaemia medicine, inhibits cyclin-dependent kinases. Nat. Cell Biol., 1, 60-67 (1999).

18) Leclerc S, Garnier M, Hoessel R, Marko D, Bibb JA, Snyder GL, Greengard P, Biernat J, Wu YZ, Mandelkow EM, Eisenbrand G, Meijer L. Indirubins inhibit glycogen synthase kinase-3 beta and CDK5/p25, two protein kinases involved in abnormal tau phosphorylation in Alzheimer's disease. A property common to most cyclin- dependent kinase inhibitors? J. Biol. Chem., 276, 251-260 (2001).

19) Vougogiannopoulou K, Ferandin Y, Bettayeb K, Myrianthopoulos V, Lozach O, Fan Y, Johnson CH, Magiatis P, Skaltsounis AL, Mikros E, Meijer L. Soluble 3',6-substituted indirubins with enhanced selectivity toward glycogen synthase kinase-3 alter circadian period. J. Med. Chem., 51, 6421-6431 (2008).

20) Pergola C, Gaboriaud-Kolar N, Jestadt N, Konig S, Kritsanida M, Schaible AM, Li H, Garscha U, Weinigel C, Barz D, Albring KF, Huber O, Skaltsounis AL, Werz O. Indirubin core structure of glycogen synthase kinase-3 inhibitors as novel chemotype for intervention with 5-lipoxygenase. J. Med. Chem., 57, 3715-3723 (2014)

21) Ichimaru Y, Saito H, Uchiyama T, Metori K, Tabata K, Suzuki T, Miyairi S. Indirubin 3'-(O-oxiran-2-ylmethyl)oxime: a novel anticancer agent. Bioorg. Med. Chem. Lett., 25, 1403-1406 (2015).

22) Kurita M, Hanada S, Ichimaru Y, Saito H, Tabata K, Asami S, Miyairi S, Suzuki T. Indirubin 3'-epoxide induces caspase-independent cell death in human neuroblastoma. Biol. Pharm. Bull., 39, 993-999 (2016).

23) Kosuge Y, Saito H, Haraguchi T, Ichimaru Y, Ohashi S, Miyagishi $\mathrm{H}$, Kobayashi S, Ishige K, Miyairi S, Ito Y. Indirubin derivatives protect against endoplasmic reticulum stress-induced cytotoxicity and down-regulate CHOP levels in HT22 cells. Bioorg. Med. Chem. Lett., 27, 5122-5125 (2017).

24) Tanaka T, Ohashi S, Saito H, Wada T, Aoyama T, Ichimaru Y, Miyairi S, Kobayashi S. Indirubin 3'-oxime inhibits anticancer agent-induced YB-1 nuclear translocation in HepG2 human hepatocellular carcinoma cells. Biochem. Biophys. Res. Commun., 496, 7-11 (2018).

25) Choi OM, Cho YH, Choi S, Lee SH, Seo SH, Kim HY, Han G, Min DS, Park T, Choi KY. The small molecule indirubin-3'-oxime activates $\mathrm{Wnt} / \beta$-catenin signaling and inhibits adipocyte differentiation and obesity. Int. J. Obes., 38, 1044-1052 (2014).

26) Saito H, Tabata K, Hanada S, Kanda Y, Suzuki T, Miyairi S. Synthesis of methoxy- and bromo-substituted indirubins and their activities on apoptosis induction in human neuroblastoma cells. Bioorg. Med. Chem. Lett., 21, 5370-5373 (2011).

27) Huang C, Zhang Y, Gong Z, Sheng X, Li Z, Zhang W, Qin Y. Berberine inhibits 3T3-L1 adipocyte differentiation through the PPARgamma pathway. Biochem. Biophys. Res. Commun., 348, 571-578 (2006).

28) Rosen ED, Walkey CJ, Puigserver P, Spiegelman BM. Transcriptional regulation of adipogenesis. Genes Dev., 14, 1293-1307 (2000).

29) Gustafson B, Jack MM, Cushman SW, Smith U. Adiponectin gene activation by thiazolidinediones requires PPAR gamma 2, but not C/EBP alpha-evidence for differential regulation of the aP2 and adiponectin genes. Biochem. Biophys. Res. Commun., 308, 933-939 (2003).

30) Guo L, Li X, Tang QQ. Transcriptional regulation of adipocyte differentiation: a central role for CCAAT/enhancer-binding protein (C/EBP) B. J. Biol. Chem., 290, 755-761 (2015).

31) Jiang D, Wang D, Zhuang X, Wang Z, Ni Y, Chen S, Sun F. Berberine increases adipose triglyceride lipase in 3T3-L1 adipocytes through the AMPK pathway. Lipids Health Dis., 15, 214-221 (2016).

32) Reilly JM, Thompson MP. Dietary fatty acids up-regulate the expression of UCP2 in 3T3-L1 preadipocytes. Biochem. Biophys. Res. Commun., 277, 541-545 (2000).

33) Yoon M. The role of PPARalpha in lipid metabolism and obesity: focusing on the effects of estrogen on PPARalpha actions. Pharmacol. Res., 60, 151-159 (2009). 